\title{
Lactotripeptides Inhibiting ACE1 Elevate the Plasma Bradykinin Concentration Acutely in a Placebo-Controlled, Double-Blind, Cross-Over, 4-Week Trial in Healthy Volunteers
}

\author{
Juerg Nussberger¹, Albin Dubach², Anu Turpeinen³, Heikki Vapaatalo4* \\ ${ }^{1}$ Department of Medicine, Angiology and Hypertension Division, Lausanne University Hospital, Lausanne, Switzerland \\ ${ }^{2}$ Emmi Schweiz AG, Luzern, Switzerland \\ ${ }^{3}$ Valio Ltd., R\&D, Helsinki, Finland \\ ${ }^{4}$ Medical Faculty, Pharmacology, University of Helsinki, Helsinki, Finland

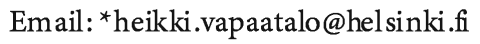

How to cite this paper: Nussberger, J., Dubach, A., Turpeinen, A. and Vapaatalo, H. (2018) Lactotripeptides Inhibiting ACE1 Elevate the Plasma Bradykinin Concentration Acutely in a Placebo-Controlled, Double-Blind, Cross-Over, 4-Week Trial in Healthy Volunteers. Pharmacology \& Pharmacy, 9, 229-241.

https://doi.org/10.4236/pp.2018.97017

Received: June 19, 2018

Accepted: July 15, 2018

Published: July 18, 2018

Copyright (ㅇ 2018 by authors and Scientific Research Publishing Inc. This work is licensed under the Creative Commons Attribution International License (CC BY 4.0).

http://creativecommons.org/licenses/by/4.0/

\begin{abstract}
This placebo-controlled, double-blind, cross-over intervention with twelve normotensive healthy volunteers tested the effects of milk products containing either 5 or $50 \mathrm{mg}$ of ACE1-inhibitory lactotripeptides (isolecine-proline-proline, Ile-Pro-Pro, and valine-proline-proline, Val-Pro-Pro) and placebo milk drink (with similar taste) on plasma bradykinin levels. The subjects consumed one of the three test products in a random order, double-blinded, and four-week trial. On the first day (day 1) and on the last day (day 29) i.e. after four weeks' treatment with one of the products, the acute effect with the same single dose was assayed. Other markers of the renin-angiotensin-aldosterone system (RAAS) were measured from plasma four times on the same days when we also assessed daytime urinary excretion of biomarkers of endothelial function. Neither acute nor prolonged administration of the ACE-1 inhibiting peptide drinks significantly lowered blood pressure of the normotensive subjects. The most important finding was the dose-dependent, and linear increase in plasma bradykinin concentrations after acute dosing on the first day; it was nearly statistically significant also on the day $29(\mathrm{p}<0.06)$. Other indicators of RAAS or endothelial function did not differ from those of placebo after the acute or prolonged treatments. Our results suggest that even weak inhibitors of ACE-1, such as the lactotripeptides Ile-Pro-Pro and Val-Pro-Pro, are able to diminish the breakdown of bradykinin and therefore increase plasma bradykinin levels. This may partly explain the blood pressure lowering and vasodilatory effects of lactotripeptides, shown by us earlier in mildly hypertensive subjects.
\end{abstract}




\section{Keywords}

Lactotripeptides, Ile-Pro-Pro, Val-Pro-Pro, Bradykinin, Blood Pressure, Human

\section{Introduction}

Fermented milk products containing casein-derived bioactive tripeptides (lactotripeptides), isoleucine-proline-proline (Ile-Pro-Pro) and valine-proline-proline (Val-Pro-Pro) have been shown to prevent the development of hypertension in different hypertensive animal models by us [1] [2] [3] and others [4] [5]. These and other similar milk products and spreads have been demonstrated to lower blood pressure in long term clinical interventions in mildly hypertensive subjects in Japanese and Finnish populations [6]-[12]. However, trials conducted in The Netherlands detected only minimal or no significant lowering of blood pressure [13] [14] [15] [16], probably, partly because the subjects after the run-in period were no longer hypertensive. Four independent meta-analyses [17] [18] [19] [20] of clinical interventions suggest that the reduction achieved with lactotripeptides in systolic blood pressure is about five $\mathrm{mmHg}$; in diastolic blood pressure it amounts to about three mmHg. In addition to the antihypertensive effect of the peptides, they reduce arterial stiffness [21] and the augmentation index in mildly hypertensive subjects [22]. The clinical findings agree with endothelium dependent vasodilatation seen in experimental studies in hypertensive rat models [23] [24] [25]. Peptide treatment improved vasodilatation induced by bradykinin ex vivo in rats possibly by acting on Mas-receptors, while the bradykinin effect was endothelium-dependent and abolished by COX inhibitors [26].

The antihypertensive mechanism of the lactotripeptides seems to be mediated mainly via ACE-1 inhibition and the reduced formation of the strongly vasoconstricting peptide, angiotensin II [4] [5] [24] [25] [26], even though other enzymes acting on the vasculature are also inhibited by these peptides [27].

Recently, an interesting hypothesis on the crucial role of bradykinin in cardioprotection and possibly in the blood pressure lowering effect of ACE-1 inhibitors has been presented. ACE-1 inhibitors have been shown to directly bind to and activate bradykinin receptors [28] [29] [30].

There are some major difficulties in investigating bradykinin's physiological and pathophysiological role in vivo i.e. its very short half-life in biological matrices, and lack of simple and reliable assays. However, a combination of liquid-phase extraction, high-performance liquid chromatography and radioimmunoassay was developed [31] and has been used reliably for assaying clinical samples [32]. The present report is the first to confirm that dietary ACE-1 inhibitory peptides may elevate the plasma bradykinin concentration in a clinical intervention in healthy normotensive subjects. 


\section{Subjects and Methods}

Twelve normotensive, non-smoking, healthy male volunteers aged 21 - 26 years participated in this cross-over, double-blind, placebo-controlled, randomized intervention study. Exclusion criteria for participation were BMI $>27 \mathrm{~kg} / \mathrm{m}^{2}$, milk allergy, lactose intolerance, smoking, alcohol or drug abuse, clinical blood abnormalities, use of prescription medicine during 30 days preceding the study and participation in any study involving blood collection during 60 days preceding the study. The protocol was approved by the Ethical Committee of the Lausanne University Hospital (protocol number 158-06).

The subjects came to the Clinical Research Unit of the University Hospital Lausanne at 7 o'clock in the morning of the intervention day. After one hour's rest, systolic and diastolic blood pressure and heart rate were measured in the sitting position. Thereafter, blood samples were drawn from the antecubital vein from the contralateral arm for measurement of bradykinin and other biochemical markers. The urinary bladder was emptied and urine was discarded.

Thereafter the subjects drank within two minutes $100 \mathrm{ml}$ of the test milk product or control (placebo) product. The test liquid product contained either 5 $\mathrm{mg}$ or $50 \mathrm{mg}$ (the sum amount) of Ile-Pro-Pro and of Val-Pro-Pro and negligible amounts (less than $0.5 \mathrm{mg}$ ) of leucine-proline-proline (Leu-Pro-Pro). The lactotripeptides were added to the test products in the form of peptide powder. The peptides were separated from Lactobacillus helveticus Lc1936 fermented milk, concentrated using nanofiltration and dried to produce a powder in Valio Ltd, Finland. The fermented placebo drink was similar (appearance and taste as far as possible), but it did not contain any measurable amounts of the peptides. The study products were provided and analysed by Valio Ltd., Finland.

After the intake of the test/placebo drink, the subjects rested in a sitting position and the blood pressure measurement was repeated after 2.5, 5 and $9 \mathrm{~h}$. After each measurement, blood samples were drawn. Urine was collected during the $10 \mathrm{~h}$ period in the ward.

A light lunch was served $4 \mathrm{~h}$ after the intake of the test/placebo drink and dinner was served after $9 \mathrm{~h}$.

The procedure was repeated similarly after 28 days' consumption of the peptide/placebo drink (at home once in the morning) containing either none, $5 \mathrm{mg}$ or $50 \mathrm{mg}$ of the peptides. These three different interventions were repeated in a random order for each subject. All procedures were double-blinded.

\subsection{Laboratory Measurements}

Bradykinin concentrations in plasma were the main outcome and were measured using the method developed originally by Nussberger et al. [31] (normal values $0.2-7.1 \mathrm{fmol} / \mathrm{ml}$ ) and used later in clinical studies [32]. Shortly, liquid-phase extraction, high-performance, liquid chromatography and RIA were applied in combination.

Plasma renin activity [33] (normal values $0.2-2.0 \mathrm{ng} / \mathrm{ml} / \mathrm{h}$ ), trapping 
ACE-activity [34] (normal values $178-475 \mathrm{fmol} / \mathrm{ml} / \mathrm{min}$ ), plasma aldosterone [35] (normal values $29-76 \mathrm{pg} / \mathrm{ml}$ ) and urinary aldosterone excretion [36] (normal values $0.5-8.0 \mu \mathrm{g} / 24 \mathrm{~h}$ ) during $10 \mathrm{~h}$ were measured in the Laboratory of Angiology and Hypertension of University Hospital Lausanne.

Additionally, urinary excretion of 6-keto-prostaglandin $\mathrm{F}_{10}$, 2,3-dinor-prostaglandin $\mathrm{F}_{1 \alpha}$ (both EIA, Cayman Chemical Co, Ann Arbor, MI, USA), the main urinary metabolites of prostacyclin $\left(\mathrm{PGI}_{2}\right)$ as well as nitrate/nitrite $\left(\mathrm{NO}_{\mathrm{X}}\right)$ (both ELISA) and cyclic GMP (R\&D Systems, Abingdon, $\mathrm{UK}$ ) as indicators of the arginine-nitric-oxide-pathway were analysed in the Medical Faculty, Department of Pharmacology, University of Helsinki from $10 \mathrm{~h}$ urine samples collected in the ward during the placebo and the high peptide dose $(50 \mathrm{mg})$ interventions. The measurements were carried out according to the manufacturers' instructions with slight modifications as in our previous study [11].

\subsection{Statistical Analyses}

The results are presented as mean with standard error of mean (SEM) or with 95 percent confidence intervals. Within-subjects analyses were done using the paired samples t-test. The information from different time points was combined by calculating the area under the curve subtracted by the baseline value $\left(\mathrm{AUC}_{0-9}\right.$ minus baseline). The statistical significance of linearity in these AUCs was tested using linear mixed models. The 95\% confidence intervals for Pearson's correlation coefficient were obtained by bootstrapping.

\section{Results}

\subsection{Blood Pressure and Heart Rate}

Because the $5 \mathrm{mg}$ dose of the peptides, administered either as an acute or continuous dosing for four weeks, did not cause any significant changes compared to the placebo drink in any of the variables, the results are presented only for the $50 \mathrm{mg}$ dose. The only exception is when the linearity of the changes is presented.

Neither blood pressure nor heart rate changed significantly vs placebo with the low or high dose of the peptides after acute dosing on either day 1 or day 29. No reduction of blood pressure was seen in the 28 days' intervention in these normotensive subjects (Table 1 ).

\subsection{Bradykinin Concentrations in Plasma}

Plasma bradykinin, the main outcome, showed quite marked inter-individual and also intra-individual variations during the day. No significant changes in the basal (morning) levels of the peptide groups vs placebo were seen after the 28 days' intervention with either peptide dose. However, the acute study (a single dose in the morning) showed clear, up to three fold higher concentrations vs the basal level in $5 \mathrm{~h}$ samples both on day $1(1.55 \pm 0.35$ to $4.76 \pm 1.03 \mathrm{fmol} / \mathrm{ml}, \mathrm{p}<$ $0.05)$ and on day $29(1.49 \pm 0.25$ to $4.05 \pm 1.00 \mathrm{fmol} / \mathrm{ml}, \mathrm{p}<0.06)$. The increase 
Table 1. Blood pressure and heart rate of 12 healthy, normotensive volunteers after the intake of a fermented milk product containing $50 \mathrm{mg}$ of lactotripeptides (Ile-Pro-Pro + Val-Pro-Pro) or placebo on day 1 and on day 29 after 4 weeks' double-blind, cross-over intervention with the same product. Results are expressed as mean +/- SEM.

\begin{tabular}{ccccc}
\hline & \multicolumn{2}{c}{ Placebo } & \multicolumn{2}{c}{ Test product } \\
\cline { 2 - 5 } & Day 1 & Day 29 & Day 1 & Day 29 \\
\hline Systolic blood pressure, mmHg & & & & \\
\hline Baseline & $118 \pm 1$ & $116 \pm 1$ & $116 \pm 2$ & $115 \pm 1$ \\
$2.5 \mathrm{~h}$ & $117 \pm 1$ & $118 \pm 2$ & $116 \pm 2$ & $117 \pm 2$ \\
$5 \mathrm{~h}$ & $117 \pm 2$ & $115 \pm 2$ & $116 \pm 2$ & $116 \pm 2$ \\
$9 \mathrm{~h}$ & $120 \pm 2$ & $119 \pm 2$ & $118 \pm 2$ & $120 \pm 2$ \\
\hline Diastolic blood pressure, mmHg & & & & \\
\hline Baseline & $66 \pm 1$ & $66 \pm 1$ & $66 \pm 1$ & $66 \pm 1$ \\
$2.5 \mathrm{~h}$ & $66 \pm 1$ & $67 \pm 1$ & $67 \pm 1$ & $67 \pm 1$ \\
$5 \mathrm{~h}$ & $65 \pm 2$ & $64 \pm 2$ & $65 \pm 1$ & $65 \pm 1$ \\
$9 \mathrm{~h}$ & $65 \pm 1$ & $67 \pm 2$ & $68 \pm 2$ & $67 \pm 1$ \\
\hline Heart rate, beats/min & & & & \\
\hline Baseline & $53 \pm 2$ & $52 \pm 1$ & $55 \pm 1$ & $55 \pm 2$ \\
$2.5 \mathrm{~h}$ & $52 \pm 2$ & $52 \pm 2$ & $55 \pm 2$ & $54 \pm 2$ \\
$5 \mathrm{~h}$ & $54 \pm 2$ & $51 \pm 1$ & $53 \pm 2$ & $51 \pm 1$ \\
\hline & $52 \pm 1$ & $56 \pm 2$ & $56 \pm 2$ & $57 \pm 3$ \\
\hline
\end{tabular}

was even more evident when the acute effect of the peptide drink was presented as $\mathrm{AUC}_{(0-9)}$ minus baseline (Figure 1(a)) and with calculation of AUC for both doses (5 and $50 \mathrm{mg}$ ) which revealed clear linearity between the doses (Figure 1 (b)). However, the statistically significant effect of $50 \mathrm{mg}$ was no longer seen on day 29.

\subsection{Other Variables of the Renin-Angiotensin-Aldosterone System (RAAS)}

Plasma renin activity remained rather stable in all treatment groups both after the acute, single administration of the placebo or peptide drinks on day 1 or 29 or with respect to chronic treatment i.e. when comparing baseline concentrations on these days (Table 2).

Baseline values for plasma trapping ACE activity were similarly stable during the 28 days' treatment period and no differences between the treatment groups were seen after a single dose (day 1 and 29) (Table 2). However, an inverse correlation between the ACE activities and bradykinin levels was evident with the $50 \mathrm{mg}$ dose on day 1 (Figure 2).

Plasma aldosterone levels remained similarly stable in all groups throughout the 28 days' treatment and in acute tests. 


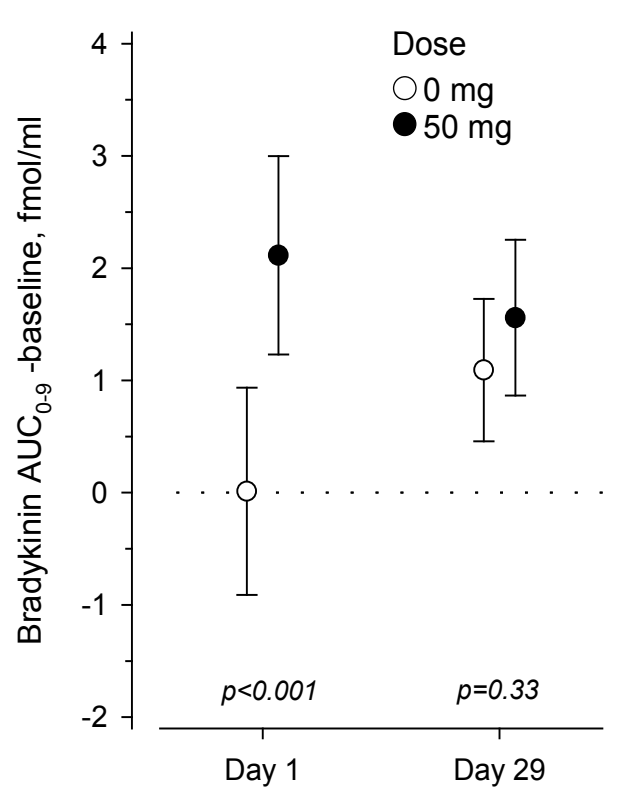

(a)
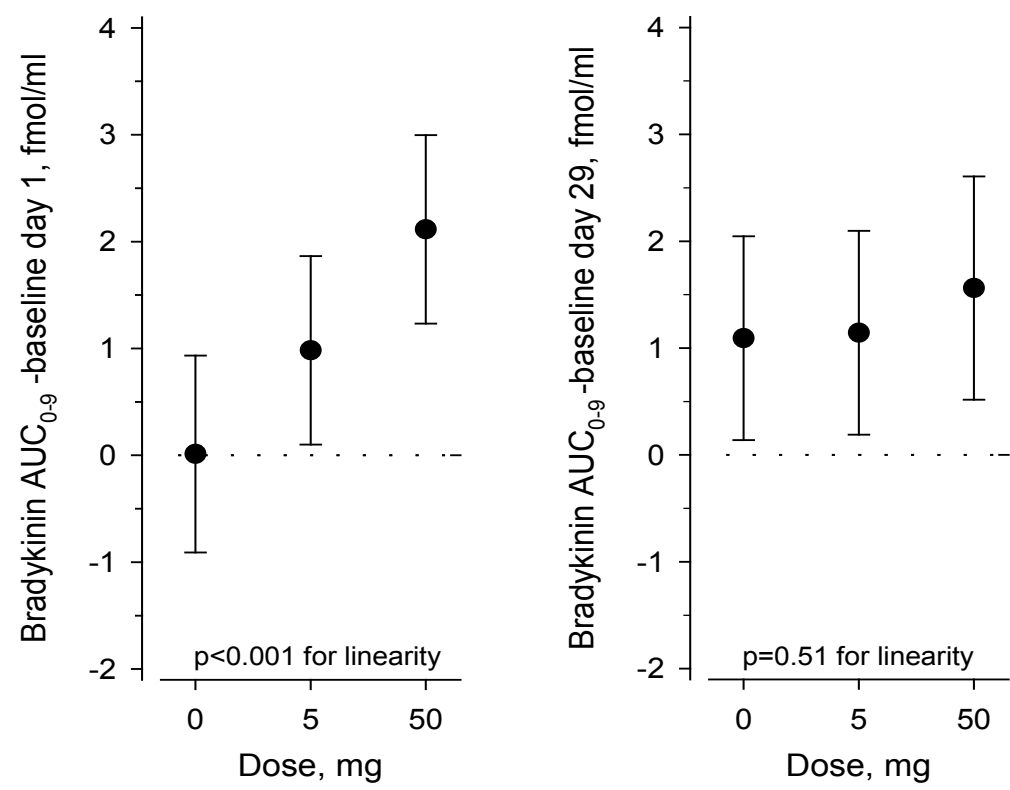

(b)

Figure 1. (a) The $\mathrm{AUC}_{0-9}$ minus baseline of plasma bradykinin concentrations $(\mathrm{n}=12)$ after the test drink containing 50 mg of tripeptides (dark dots) or placebo drink without peptides (open circles) on day 1 and day 29 after 4 weeks' double-blind, cross-over intervention. Results are expressed as means with 95\% intervals. (b) Linearity of the $\mathrm{AUC}_{0-9}$ minus baseline of plasma bradykinin concentrations $(n=12)$ after a single dose of the test drinks containing 5 or $50 \mathrm{mg}$ of the tripeptides on day 1 and day 29 after 4 weeks' double-blind, cross-over intervention with the same daily dosages. Results are presented as means with $95 \%$ intervals.

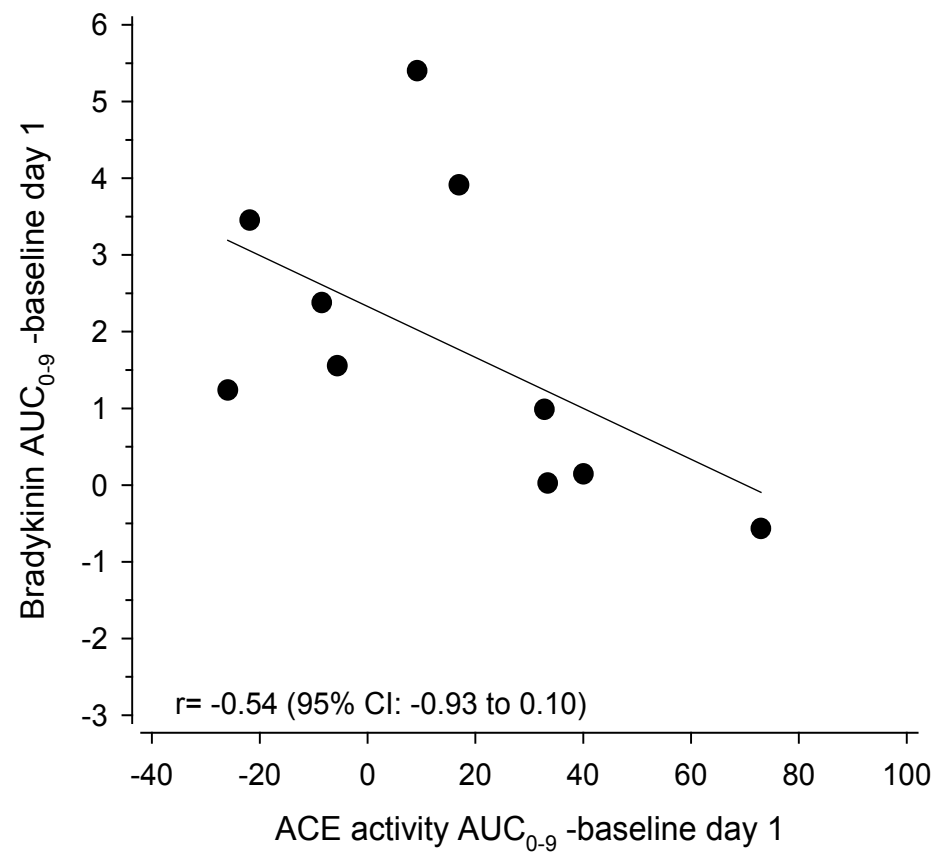

Figure 2. The relationship between individual plasma bradykinin concentrations $\left(\mathrm{AUC}_{0-9}\right.$ minus baseline) and plasma trapping $\mathrm{ACE}$ activity $\left(\mathrm{AUC}_{0-9}\right.$ minus baseline) on day 1 , when bradykinin concentrations increased after a single dose of the test drink containing $50 \mathrm{mg}$ of the tripeptides. 
Table 2. Variables of renin-angiotensin-aldosterone system (RAAS) of 12 healthy volunteers after the intake of a fermented milk product containing $50 \mathrm{mg}$ of lactotripeptides (Ile-Pro-Pro + Val-Pro-Pro) or placebo on day 1 and on day 29 after 4 weeks' double-blind, cross-over intervention with the same product. Results are expressed as mean +/- SEM.

\begin{tabular}{ccccc}
\hline & \multicolumn{2}{c}{ Placebo } & \multicolumn{2}{c}{ Test product } \\
\cline { 2 - 5 } & Day 1 & Day 29 & Day 1 & Day 29 \\
\hline Plasma renin activity, ng/ml/h & & & & \\
\hline Baseline $(0 \mathrm{~h})$ & $0.65 \pm 0.08$ & $0.69 \pm 0.15$ & $0.63 \pm 0.12$ & $0.55 \pm 0.09$ \\
$2.5 \mathrm{~h}$ & $0.74 \pm 0.12$ & $0.85 \pm 0.18$ & $0.76 \pm 0.10$ & $0.63 \pm 0.14$ \\
$5 \mathrm{~h}$ & $0.80 \pm 0.08$ & $0.69 \pm 0.17$ & $0.67 \pm 0.11$ & $0.45 \pm 0.12$ \\
$9 \mathrm{~h}$ & $0.61 \pm 0.11$ & $0.61 \pm 0.10$ & $0.58 \pm 0.09$ & $0.53 \pm 0.10$ \\
\hline Plasma trapping ACE activity, fmol/ml/min & & & & \\
\hline Baseline & $429 \pm 22$ & $421 \pm 23$ & $418 \pm 25$ & $431 \pm 26$ \\
$2.5 \mathrm{~h}$ & $439 \pm 24$ & $414 \pm 35$ & $440 \pm 30$ & $446 \pm 30$ \\
$5 \mathrm{~h}$ & $434 \pm 22$ & $436 \pm 23$ & $442 \pm 22$ & $451 \pm 25$ \\
$9 \mathrm{~h}$ & $417 \pm 23$ & $432 \pm 23$ & $421 \pm 26$ & $435 \pm 26$ \\
\hline Plasma aldosterone, pg/ml & & & & \\
\hline Baseline & & & & \\
$2.5 \mathrm{~h}$ & $50.8 \pm 3.4$ & $54.8 \pm 4.8$ & $49.5 \pm 3.4$ & $52.6 \pm 4.2$ \\
$5 \mathrm{~h}$ & $67.7 \pm 8.3$ & $65.4 \pm 10.4$ & $68.4 \pm 8.7$ & $60.2 \pm 5.0$ \\
\hline & $49.1 \pm 3.9$ & $46.4 \pm 4.4$ & $50.0 \pm 7.3$ & $45.8 \pm 4.3$ \\
& $45.6 \pm 4.1$ & $46.6 \pm 4.7$ & $53.4 \pm 7.2$ & $61.8 \pm 8.3$ \\
\hline
\end{tabular}

Urine aldosterone excretion during the $10 \mathrm{~h}$ collection period varied from subject to subject, but remained at about the same level independent of the treatment (Table 3). A non-significant tendency for linearity $(0,5$ and $50 \mathrm{mg}$ peptides; $\mathrm{p}=0.083$ ) was seen on day 1 (data not shown).

Urinary markers of the vascular arachidonic acid and nitric oxide pathways are presented in Table 3. The basal excretion of prostacyclin metabolites 6-ketoPGF $\mathrm{F}_{1 \alpha}$ and 2,3-dinor 6-ketoPGF ${ }_{1 \alpha}$ remained at the same level on day 1 and day 29 , and the $50 \mathrm{mg}$ peptide dose did not cause any change in these values (Table 3). This was also the situation for urinary excretion of nitrate/nitrite and cyclic GMP (Table 3).

\section{Discussion}

The blood pressure lowering effect of milk casein-derived bioactive tripeptides (lactotripeptides) has been demonstrated in animal models [1] [2] [3] [4] [23] [24] [25] as well as in humans (see meta-analyses 18 - 20). The antihypertensive mechanism has been related to ACE1 inhibition [4] [5] [23] [24] [25] and further less formation of angiotensin II, which at least partly explains the favourable effects. However, another mechanism of vasoactive components on the 
Table 3. Excretion of biomarkers of endothelial function in urine collected over $10 \mathrm{~h}$ from healthy normotensive volunteers $(n=12)$ after the intake of a fermented milk product containing $50 \mathrm{mg}$ of lactotripeptides (Ile-Pro-Pro + Val-Pro-Pro) or placebo on day 1 and on day 29 after 4 weeks' double-blind, cross-over, intervention with the same product and dose. Results are expressed as mean $+/-$ SEM.

\begin{tabular}{|c|c|c|c|c|}
\hline & \multicolumn{2}{|c|}{ Placebo } & \multicolumn{2}{|c|}{ Test product } \\
\hline & Day 1 & Day 29 & Day 1 & Day 29 \\
\hline Urine aldosterone, $\mu \mathrm{g}$ & $1.66 \pm 0.21$ & $1.83 \pm 0.29$ & $2.34 \pm 0.44$ & $1.90 \pm 0.29$ \\
\hline Urine 6-keto-PGF ${ }_{1 \alpha}$, ng & $604 \pm 40$ & $793 \pm 86$ & $660 \pm 75$ & $1040 \pm 323$ \\
\hline Urine 2,3-dinor-6-keto-PGF ${ }_{1 \infty} \mu \mathrm{g}$ & $12.1 \pm 1.2$ & $13.8 \pm 2.9$ & $13.6 \pm 1.5$ & $13.4 \pm 0.8$ \\
\hline Urine nitrate/nitrite, $\mathrm{mmol}$ & $1130 \pm 233$ & $1080 \pm 175$ & $1131 \pm 211$ & $921 \pm 106$ \\
\hline Urine cGMP, nmol & $263 \pm 18$ & $246 \pm 17$ & $239 \pm 20$ & $238 \pm 15$ \\
\hline
\end{tabular}

renin-angiotensin system is mediated via bradykinin, whose role until now has been obscure and less extensively studied. Here we approached this issue by measuring plasma bradykinin levels of healthy normotensive subjects after a single dose of fermented milk products containing two concentrations of the lactotripeptides Ile-Pro-Pro and Val-Pro-Pro. The effects of acute dosing were tested on the first and last days of a trial where the volunteers consumed the peptide drinks on a daily basis for four weeks.

Strict and controlled condition was a strength of the study. The subjects spent the whole test day at the ward, drinking and eating were similar each time. Blood pressure measurement and blood sampling were done by the same nurse. The compliance of the consumption of test drinks was excellent. The clinical chemistry measurements were done every time in the same laboratories.

The main finding was that the plasma bradykinin concentration increased dose-dependently after a single dose of the peptide drink on the first, but interestingly, not quite significantly $(\mathrm{p}<0.06)$ on the last day after daily use of the test product for four weeks. This can be explained by a kinetic "steady state" of plasma levels of the peptides and their, previously described in an animal study [37]. Thus, on the last day, the acute dosing could no longer exert any significant, measurable effect on this very labile biomarker. Even then, a clear tendency towards an increase in $5 \mathrm{~h}$ blood samples was seen with the higher dose $(50 \mathrm{mg})$. Furthermore, with this dose, a negative correlation between bradykinin and ACE1 activity was found on the first day after a single dosing, indicating that there had been clinical inhibition of ACE1. Unfortunately, we were not able to measure active metabolites of bradykinin, such as bradykinin (1 - 5) and (1 - 7) [38] [39]. In fact, the role of the different breakdown products of bradykinin in the antihypertensive mechanism of ACE inhibitors is still a matter of discussion [29] [30].

No changes in blood pressure were seen with either the chronic or acute dosing of the peptide drinks, which can be explained by the fact that the subjects in this trial had normal blood pressure and were not hypertensive as in many trials 
where blood pressure lowering effect has been shown [6]-[12]. The lack of blood pressure reduction in the present study is in agreement with some earlier studies where the subjects have been nearly normotensive [13] [14] [15] [16]. No treatment related adverse effects were described by the subjects during the whole trial which lasted three months with three different doses (placebo, 5 or $50 \mathrm{mg}$ of peptides).

We were unable to detect any other treatment effects which could have strengthened these observations of the possible role of bradykinin on its endothelial second messengers such as prostacyclin or on the NO/cyclic GMP pathway. This can be attributable to different factors: firstly, the peptides are too weak ACE-inhibitors to cause measurable changes in variables whose measurement is not only technically difficult but also subject to significant inter-individual and even intra-individual variations; secondly, our healthy, normotensive group was small and bigger changes would have been required for statistically significant differences; thirdly, due to the young age of the volunteers, their cardiovascular system was able to balance possible circulatory effects of the peptides; fourthly, the observed changes in these parameters were too small and clinical effects of the lactotripeptides were not expected in healthy volunteers consuming a regular diet.

However, in our recent experimental study conducted in spontaneously hypertensive rats, in addition to antihypertensive effects, we were able to demonstrate also a marked improvement of endothelium dependent relaxation of mesenteric artery rings by bradykinin in the presence of Ile-Pro-Pro [26]. This may indicate that even though we were not able to observe all of the potential changes in the measured markers of the bradykinin system with weak ACE inhibitory peptides, they may act at the functional level synergistically with bradykinin or the effects may be mediated via the active metabolites of bradykinin [38] [39].

Interestingly, the chemical structure of the first peptide type ACE inhibitor, teprotide, indicates that the carboxy terminal in the tripeptide Ile-Pro-Pro configuration is similar to that present seen in a bradykinin potentiator, B [40]. These observations bring the studied peptides closer to the bradykinin pathway.

Furthermore, treatment with ACE inhibitors has been shown to affect the bradykinin type 2 receptors responsible for vasodilatation [41] [42], and this would then augment the beneficial vascular effects of bradykinin, i.e. they would not simply be mediated by preventing the breakdown of bradykinin.

At the cellular level, vascular effects of bradykinin have been suggested to be mediated by stimulation of NO and prostacyclin formation [43]. These mediators were not found to be elevated in the urine collected during the period when bradykinin levels were increased in plasma. This discrepancy can possibly be explained by the quite large variations in their levels and these can be due to either individual or methodological issues i.e., urine without chromatographic separation is not the best matrix for these kinds of measurements. Furthermore, urinary levels probably reflect the long-term balance and changes of these vascular 
endothelium-derived variables better than plasma.

Taken together, our present observations with information from the literature and from our earlier experimental findings, suggest that at least part of the favourable vascular effects of ACE-inhibitory lactotripeptides can be associated with bradykinin; these may be mediated in many different ways, and furthermore, it is probable that they act synergistically in the same direction.

\section{Acknowledgements}

The study was supported by Valio Ltd, Finland and Emmi AG, Switzerland We are grateful to Anne Kivimäki, BSc and Laura Piirainen, $\mathrm{MD}, \mathrm{PhD}$ for their valuable technical help and Salme Järvenpää, MSc for statistical analyses. The contributions of Professor Riitta Korpela and Tiina Jauhiainen, PhD from Valio Ltd, Finland in the planning and conduction of the study are greatly appreciated. Dr. Ewen MacDonald is acknowledged for checking the language and grammar.Grant (HV) from Finska Läkaresällskapet, Einar och Karin Stroem's Foundation is acknowledged.

\section{References}

[1] Sipola, M., Finckenberg, P., Santisteban, J., Korpela, R., Vapaatalo, H. and Nurminen, M.L. (2001) Long-Term Intake of Milk Peptides Attenuates Development of Hypertension in Spontaneously Hypertensive Rats. Journal of Physiology and Pharmacology, 52, 745-754.

[2] Jauhiainen, T., Collin, M., Narva, M., Poussa, T., Cheng, J.Z., Poussa, T., et al. (2005) Effect of Long-Term Intake of Milk Peptides and Minerals on Blood Pressure and Arterial Function in Spontaneously Hypertensive Rats. Milchwissenschaft, 60, 358-363.

[3] Jäkälä, P., Hakala, A., Turpeinen, A., Korpela, R. and Vapaatalo, H. (2009) Casein-Derived Bioactive Tripeptides Ile-Pro-Pro and Val-Pro-Pro Attenuate the Development of Hypertension and improve Endothelial Function in Salt-Loaded Goto-Kakizaki Rats. Journal of Functional Foods, 1, 366-374.

https://doi.org/10.1016/j.jff.2009.09.003

[4] Yamamoto, N., Akino, A. and Takano, T. (1994) Antihypertensive Effect of the Peptides Derived from Casein by an Extracellular Proteinase from Lactobacillus helveticus CP790. Journal of Dairy Science, 77, 917-922. https://doi.org/10.3168/jds.S0022-0302(94)77026-0

[5] Nakamura, Y., Yamamoto, N., Sakai, K. and Takano, T. (1995) Antihypertensive Effect of Sour Milk And Peptides Isolated from It That Are Inhibitors to Angiotensin I-Converting Enzyme. Journal of Dairy Science, 78, 1253-1257. https://doi.org/10.3168/jds.S0022-0302(95)76745-5

[6] Hata, Y., Yamamoto, M., Ohni, M., Nakajima, K., Nakamura, Y. and Takano, T. (1996) A Placebo-Controlled Study of the Effect of Sour Milk on Blood Pressure in Hypertensive Subjects. The American Journal of Clinical Nutrition, 64, 767-771. https://doi.org/10.1093/ajcn/64.5.767

[7] Kajimoto, O., Kurosaki, T., Mizutani, J., Nagisa, I., Kaneko, K., Aihara, K., et al. (2002) Antihypertensive Effects of Liquid Yogurts Containing "Lactotripeptides (VPP, IPP)" in Mild Hypertensive Subjects. Journal of Nutrition and Food, 5, 55-66.

[8] Seppo, L., Kerojoki, O., Suomalainen, T. and Korpela, R. (2002) The Effect of a 
Lactobacillus helveticus LBK-16H Fermented Milk on Hypertension-A Pilot Study on Humans. Milchwissenschaft, 57, 124-127.

[9] Tuomilehto, J., Lindström, J., Hyyrynen, J., Korpela, R., Karhunen, M.L., Mikkola, L., et al. (2004) Effect of Ingesting Sour Milk Fermented Using Lactobacillus helveticus Bacteria Producing Tripeptides on Blood Pressure in Subjects with Mild Hypertension. Journal of Human Hypertension, 18, 795-802. https://doi.org/10.1038/sj.jhh.1001745

[10] Jauhiainen, T., Vapaatalo, H., Poussa, T., Kyrönpalo, S., Rasmussen, M. and Korpela, R. (2005) Lactobacillus helveticus Fermented Milk Lowers Blood Pressure in Hypertensive Subjects in 24-h Ambulatory Blood Pressure Measurement. American Journal of Hypertension, 18, 1600-1605. https://doi.org/10.1016/j.amjhyper.2005.06.006

[11] Turpeinen, A.M., Ehlers, P.I., Kivimäki, A.S., Järvenpää, S., Filler, I., Wiegert, E., et al. (2011) Ile-Pro-Pro and Val-Pro-Pro Tripeptide-Containing Milk Product Has Acute Blood Pressure Lowering Effects in Mildly Hypertensive Subjects. Clinical and Experimental Hypertension, 33, 388-396. https://doi.org/10.3109/10641963.2010.549267

[12] Turpeinen, A.M., Ikonen, M., Kivimäki, A., Kautiainen, H., Vapaatalo, H. and Korpela, R. (2012) A Spread Containing Bioactive Peptides Ile-Pro-Pro and Val-Pro-Pro, and Plant Sterols Has Antihypertensive and Cholesterol Lowering Effects. Food \& Function, 6, 621-627. https://doi.org/10.1039/c2fo10286b

[13] van der Zander, K., Bots, M.L., Bak, A.A.A., Koning, M.M.G. and de Leeuw, P.W. (2008) Enzymatically Hydrolyzed Lactotripeptides Do Not Lower Blood Pressure in Mildly Hypertensive Subjects. The American Journal of Clinical Nutrition, 88, 1697-1702. https://doi.org/10.3945/ajcn.2008.26003

[14] Engberink, M.F., Schouten, E.G., Kok, F.J., van Mierlo, L.A.J., Brouwer, I.A. and Geleijnse, J.M. (2008) Lactotripetides Show No Effect in Human Blood Pressure. Hypertension, 51, 399-405. https://doi.org/10.1161/HYPERTENSIONAHA.107.098988

[15] van Mierlo, L.A.J., Koning, M.M.G., van der Zander, K. and Draijer, R. (2009) Lactotripeptides Do Not Lower Blood Pressure in Untreated Whites: Results from 2 Controlled Multicenter Crossover Studies. The American Journal of Clinical Nutrition, 89, 617-623. https://doi.org/10.3945/ajcn.2008.26918

[16] Geleijnse, J.M. and Engberink, M.F. (2010) Lactopeptides and Human Blood Pressure. Current Opinion in Lipidology, 21, 58-63. https://doi.org/10.1097/MOL.0b013e3283333813

[17] Pripp, A.H. (2008) Effect of Peptides Derived from Food Proteins on Blood Pressure: A Meta-Analysis of Randomized Controlled Trials. Food \& Nutrition Research, 52.

[18] Xu, J.Y., Qin, L.Q., Wang, P.Y., Li, W. and Chang, C. (2008) Effect of Milk Tripeptides on Blood Pressure: A Meta-Analysis of Randomized Controlled Trials. Nutrition, 24, 933-940. https://doi.org/10.1016/j.nut.2008.04.004

[19] Cicero, A.F.G., Gerocarni, B., Laghi, L. and Borghi, C. (2010) Blood Pressure Lowering Effect of Lactotripeptides Assumed as Functional Foods: A Meta-Analysis of Current Available Clinical Trials. Journal of Human Hypertension, 25, 1-12.

[20] Turpeinen, A.M., Järvenpää, S., Kautiainen, H., Korpela, R. and Vapaatalo, H. (2013) Antihypertensive Effects of Bioactive Tripeptides-A Random Effects Meta-Analysis. Annals of Medicine, 45, 51-56. https://doi.org/10.3109/07853890.2012.663926 
[21] Jauhiainen, T., Rönnback, M., Vapaatalo, H., Wuolle, K., Kautiainen, H. and Korpela, R. (2007) Lactobacillus helveticus Fermented Milk Reduces Arterial Stiffness in Hypertensive Subjects. International Dairy Journal, 17, 1209-1211. https://doi.org/10.1016/j.idairyj.2007.03.002

[22] Jauhiainen, T., Rönnback, M., Vapaatalo, H., Wuolle, K., Kautiainen, H., Groop, P.-E., et al. (2002) Long-Term Intervention with Lactobacillus helveticus Fermented Milk Improves Arterial Stiffness in Hypertensive Subjects. European Journal of Clinical Nutrition, 64, 424-431. https://doi.org/10.1038/ejcn.2010.3

[23] Sipola, M., Finckenberg, P., Korpela, R., Vapaatalo, H. and Nurminen, M.L. (2010) Effect of Long-Term Intake of Milk Products on Blood Pressure in Hypertensive Rats. Journal of Dairy Research, 69, 103-111. https://doi.org/10.1017/S002202990100526X

[24] Jäkälä, P., Pere, E., Lehtinen, R., Turpeinen, A., Korpela, R. and Vapaatalo, H. (2009) Cardiovascular Activity of Milk Casein-Derived Tripeptides and Plant Sterols in Spontaneously Hypertensive Rats. Journal of Physiology and Pharmacology, 60, 11-20.

[25] Jäkälä, P., Hakala, A., Turpeinen, A.M., Korpela, R. and Vapaatalo, H. (2009) Casein Derived Bioactive Tripeptides Ile-Pro-Pro and Val-Pro-Pro Attenuate the Development of Hypertension and Improve Endothelial Function in Salt-Loaded Goto-Kakizaki Rats. Journal of Functional Foods, 1, 366-374. https://doi.org/10.1016/j.jff.2009.09.003

[26] Siltari, A., Korpela, R. and Vapaatalo, H. (2016) Bradykinin-Induced Vasodilatation: Role of Age, ACE1-Inhibitory Peptide, Mas- and Bradykinin Receptors. Peptides, 85, 46-55. https://doi.org/10.1016/j.peptides.2016.09.001

[27] Siltari, A., Kivimäki, A.S., Ehlers, P.I., Korpela, R. and Vapaatalo, H. (2012) Effects of Milk Casein Derived Tripeptides on Endothelial Enzymes in Vitro: A Study with Synthetic Tripeptides. Drug Research, 62, 477-481.

https://doi.org/10.1055/s-0032-1321846

[28] Gnjatovic, T., Tan, F., Brovkovych, V., Skidgel, R.A. and Erdos, E.G. (2002) Novel Mode of Action of Angiotensin I Converting Enzyme Inhibitors. Direct Activation of Bradykinin $B_{1}$ Receptor. The Journal of Biological Chemistry, 277, 16847-16852. https://doi.org/10.1074/jbc.M200355200

[29] Taddei, S. and Bortolotto, L. (2016) Unraveling the Pivotal Role of Bradykinin in ACE Inhibitor Activity. American Journal of Cardiovascular Drugs, 16, 309-321. https://doi.org/10.1007/s40256-016-0173-4

[30] Ceconi, C., Francolini, G., Olivares, A., Comini, L., Bachetti, T. and Ferrari, R. (2007) Angiotensin-Converting Enzyme (ACE) Inhibitors Have Different Selectivity for Bradykinin Binding Sites of Human Somatic ACE. European Journal of Pharmacology, 577, 1-6.

[31] Nussberger, J., Cugno, M., Amstutz, C., Cicardi, M., Pellacani, A. and Agostoni, A. (1998) Plasma Bradykinin in Angio-Oedema. The Lancet, 351, 1693-1697. https://doi.org/10.1016/S0140-6736(97)09137-X

[32] Cugno, M., Agostoni, P., Mari, D., Meroni, P.L., Gregorini, L., Bussetti, M., et al. (2005) Impaired Bradykinin Response to Ischemia and Exercise in Patients with Mild Congestive Heart Failure during Angiotensin-Converting Enzyme Treatment. Relationships with Endothelial Function, Coagulation and Inflammation. British Journal of Haematology, 130, 113-120. https://doi.org/10.1111/j.1365-2141.2005.05569.x

[33] Nussberger, J., Fasanella d'Amore, T., Porchet, M., Waeber, B., Brunner, D.B., 
Brunner, H.R., et al. (1987) Repeated Administration of the Converting Enzyme Inhibitor Cilazapril to Normal Volunteers. Journal of Cardiovascular Pharmacology, 9, 39-44. https://doi.org/10.1097/00005344-198701000-00007

[34] Nussberger, J., Brunner, D., Keller, I. and Brunner, H.R. (1992) Measurement of Converting Enzyme Activity by Antibody-Trapping of Generated Angiotensin II. Comparison with Two Other Methods. American Journal of Hypertension, 5, 393-398. https://doi.org/10.1093/ajh/5.6.393

[35] Nussberger, J., Waeber, B., Brunner, H.R., Burris, J.F. and Vetter, W. (1984) Highly Sensitive Microassay for Aldosterone in Unextracted Plasma Comparison with Two Other Methods. Journal of Laboratory and Clinical Medicine, 104, 789-796.

[36] Nussberger, J., Wuerzner, G., Jensen, C. and Brunner, H.R. (2002) Angiotensin II Suppression in Humans by the Orally Active Renin Inhibitor Aliskren (SPP100). Comparison with Enalapril. Hypertension, 39, e1-e8.

https://doi.org/10.1161/hy0102.102293

[37] Jauhiainen, T., Wuolle, K., Vapaatalo, H., Kerojoki, O., Nurmela, K., Lowrie, C., et al. (2007) Oral Absorption, Tissue Distribution and Excretion of a Radiolabeled Analog of a Milk-Derived Antihypertensive Peptide, Ile-Pro-Pro, in Rats. International Dairy Journal, 17, 1216-1223. https://doi.org/10.1016/j.idairyj.2007.02.004

[38] Murphey, L.J., Hachey, D.L., Oates, J.A., Morrow, J.D. and Brown, N.J. (2000) Metabolism of Bradykinin in Vivo in Humans: Identification of MK 1-5 as a Stable Plasma Peptide Metabolite. Journal of Pharmacology and Experimental Therapeutics, 294, 263-269.

[39] Bujak-Glzycka, B., Olszanecki, R., Madej, J., Suski, M., Gebska, A. and Korbut, R. (2011) Metabolism of Bradykinin in Aorta of Hypertensive Rats. Acta Biochimica Polonica, 58, 199-202.

[40] Teprotide. Cell Signaling \& Neuroscience, Sigma-Aldrich Catalogue 2002-2003. 681.

[41] Marcic, B., Deddish, P.A., Skidgel, R.A., Erdös, E.G., Minshall, R.D. and Tan, F. (2000) Replacement of the Transmembrane Anchor in Angiotensin I-Converting Enzyme (ACE) with a Glycosylphosphatidylinositol Tail Affects Activation of the B2 Bradykinin Receptor by ACE Inhibitors. The Journal of Biological Chemistry, 275, 16110-16118. https://doi.org/10.1074/jbc.M909490199

[42] Minshall, R.D., Tan, F., Nakamura, F., Rabito, S.F., Becker, R.P., Marcic, B. and Erdös, E.G. (1997) Potentiation of the Actions of Bradykinin by Angiotensin I-Converting Enzyme Inhibitors. The Role of Expressed Human Bradykinin B2 Receptors and Angiotensin I-Converting Enzyme in CHO Cells. Circulation Research, 81, 848-856. https://doi.org/10.1161/01.RES.81.5.848

[43] Gauthier, K.M., Cepura, C.J. and Campbell, W.B. (2013) ACE Inhibition Enhances Bradykinin Relaxations through Nitric Oxide and B1 Receptor Activation in Bovine Coronary Arteries. Biological Chemistry, 394, 1205-1212.

https://doi.org/10.1515/hsz-2012-0348 